\title{
Association of ORAI1 Genetic Polymorphism with Serum Calcium and Phosphorus Levels in Non-dialysis Chronic Kidney Disease Patients: A Case-control Study
}

Ishrat Jahan ${ }^{1}$, Salma Ahmed ${ }^{1}$, Md Rabiul Islam ${ }^{1}$, Abu Noim Md Abdul Hai ${ }^{2}$, Mohammad Faijul Islam ${ }^{3}$, Mohiuddin Ahmed Bhuiyan ${ }^{1}$, Zabun Nahar ${ }^{1}$

1. Pharmacy, University of Asia Pacific, Dhaka, BGD 2. Nephrology, National Institute of Kidney Diseases and Urology, Dhaka, BGD 3. Nephrology, Holy Family Red Crescent Medical College Hospital, Dhaka, BGD

Corresponding author: Md Rabiul Islam, robi.ayaan@gmail.com

\section{Abstract}

\section{Background}

As chronic kidney disease (CKD) is a silent killer, it is now a global concern to find out the possible causes by genetic and biological markers. In the earlier stages of CKD, serum calcium and phosphorus levels fall down later on turned into hypercalcemia and hyperphosphatemia contributing high mortality in CKD. This study aimed to examine the serum calcium and phosphorus levels in non-dialysis CKD patients and healthy controls to find out their association with ORAI1 genetic polymorphism.

\section{Methods}

The present study recruited 96 non-dialysis CKD patients and 100 control subjects matched by age, gender, and body mass index (BMI). Measurement of serum calcium levels was performed with atomic absorption spectrophotometer (HITACHI, 170-30) and phosphorus levels were determined by UV VIS spectrophotometer (Analytik Jena SPEKOL 2000). PCR-RFLP technique was applied to determine the genetic polymorphism of ORAI1 (rs12313273 and rs6486795) gene.

\section{Results}

The mean values of serum calcium and phosphorus levels were $2.53 \pm 0.50 \mathrm{mg} / \mathrm{dL}$ and $3.77 \pm$

Received 04/16/2019 Review began 04/18/2019 Review ended 04/24/2019 Published 04/29/2019

\section{(c) Copyright 2019}

Jahan et al. This is an open access article distributed under the terms of the Creative Commons Attribution License CC-BY 3.0., which permits unrestricted use, distribution, and reproduction in any medium, provided the original author and source are credited.
$0.42 \mathrm{mg} / \mathrm{dL}$ for the patient group and $3.67 \pm 2.37 \mathrm{mg} / \mathrm{dL}$ and $13.66 \pm 6.34 \mathrm{mg} / \mathrm{dL}$ for the control group, respectively. We observed significantly reduced serum calcium and phosphorus levels in non-dialysis CKD patients compared with control subjects $(p<0.001)$. No significant polymorphism of ORAI1 (rs12313273 and rs6486795) was found with declined serum calcium and phosphorus levels.

\section{Conclusions}

The present study suggested that there is no linear correlation between ORAI1 genetic polymorphism with serum calcium and phosphorus levels in non-dialysis CKD patients.

\section{How to cite this article}

Jahan I, Ahmed S, Islam M, et al. (April 29, 2019) Association of ORAl1 Genetic Polymorphism with Serum Calcium and Phosphorus Levels in Non-dialysis Chronic Kidney Disease Patients: A Case-control Study. Cureus 11(4): e4564. DOI 10.7759/cureus.4564 
Categories: Genetics, Urology, Nephrology

Keywords: orai1, genetic polymorphism, serum, calcium, phosphorus, ckd

\section{Introduction}

Chronic kidney disease (CKD) is a noteworthy reason for morbidity and mortality worldwide [12]. With the increasing prevalence around the globe, CKD has become a major public health problem. In America, approximately 11\% to 15\% of people have CKD [3]. According to Hill et al., the global prevalence of CKD is between $11 \%$ and $13 \%$, and the majority of them are at stage 3 [4]. In Bangladesh, the data regarding CKD prevalence is scarce, whereas a recent study found that there was a high prevalence of CKD in urban middle-income Bangladeshis. They reported that one in every five middle-income urban Bangladeshis has CKD [5]. This number can be attributed to the fact that most of the traditional and non-traditional risk factors of CKD (diabetes, hypertension, and anemia) are seen in the majority of the people of Bangladesh.

The most prominent cause of death in CKD is cardiovascular complications [6-7]. Compared to the general population, cardiovascular disease is $10-20$ folds higher in dialysis patients manifested by elevated serum calcium, hyperphosphatemia, secondary hyperparathyroidism, and ultimately vascular calcification contributing excess mortality in CKD [3,6,8-11]. For all the life-sustaining physiologic processes, tight control of calcium and phosphate homeostasis is mandatory [12]. Cell phosphate is considered as at the core of all energy-dependent physiologic process, whereas virtually all cellular functions such as modulation of the immune response, activation of inflammation, enzyme metabolism, muscle contraction, etc. are involved in the calcium-dependent pathway [12-13]. The capability of kidney controlling calcium varies according to different stages of CKD [14]. In dialysis patients, normal homeostasis of both calcium and phosphorus is compromised, resulting to hypercalcemia, hyperphosphatemia, elevated calcium phosphate products, high parathyroid hormone (PTH), and worsen secondary parathyroidism (SHPT) through a direct and indirect mechanism. However, in non-dialysis CKD patients, the association between serum phosphate levels and mortality has not been explored yet [10].

Genetic screening and linkage analysis in patients with defects in calcium release-activated calcium (CRAC) channel identified the association of ORAI1 [15]. ORAI1 is a tetra-spanning plasma membrane protein that forms the ion-conducting pore of CRAC channel. Recently, Hwang et al. demonstrated the association of ORAI1 gene polymorphism in the Taiwanese population by investigating five ORAI1 tSNPs (rs12313273, rs6486795, rs7135617, rs12320939, and rs712853). From their study, single nucleotide polymorphism of rs12313273 was found to be extensively linked with high serum calcium levels [13]. Besides, the association between inflammation and CKD has been explored in several studies. It is reported that racial variation is obvious for the susceptibility to renal disease and Indo-Asian origin have a greater risk of mounting end-stage renal disease than Caucasians [16]. There is no previous study concerning the association between genetic polymorphism of the ORAl1 gene and serum calcium and phosphorus levels among CKD patients in Bangladesh. The aim of this study was to examine the association of genetic polymorphisms of the ORAI1 gene with serum calcium and phosphorus levels in Bangladeshi non-dialysis CKD patients.

\section{Materials And Methods}

\section{Study population}

This case-control study enrolled in 96 non-dialysis CKD patients and one hundred healthy individuals. The patients were recruited from the National Institute of Kidney Diseases and Urology (NIKDU), Dhaka, Bangladesh and Department of Nephrology, Holy Family Red Crescent Medical College Hospital (HFRCMCH), Dhaka, Bangladesh. Qualified nephrologists diagnosed CKD patients by applying necessary procedures and laboratory tests. The healthy 
individuals were recruited from the same catchment area matched by age, gender, and body mass index (BMI). These study participants were free from any other severe illness. All subjects were assessed through a detail medical history to exclude any systemic diseases that can interfere with the serum calcium or phosphorus levels or genetic polymorphisms of the ORAI1 gene. Additional exclusion criteria were alcohol or substance abuse, mental retardation, psychiatric illness, and the presence of infectious disease.

\section{Blood sample collection}

Blood samples $(5 \mathrm{ml})$ were drawn from the cephalic vein of each subject using a syringe fitted with a stainless steel needle. For serum calcium and phosphorus analysis, the collected blood was allowed to clot for at least one hour at room temperature and then centrifuge at $1000 \mathrm{x} \mathrm{g} 15$ minutes to separate the serum. The serum samples were placed into microtubes and stored at $80^{\circ} \mathrm{C}$ until quantitative analysis. On the other hand, for genetic analysis, the blood samples were transferred within vacuum tubes containing EDTA (ethylenediaminetetraacetic acid) and stored into the refrigerator at $-20^{\circ} \mathrm{C}$.

\section{DNA extraction and quantification}

Genomic DNA was extracted by blood genomic DNA extraction mini kit (Favorgen, Taiwan) as per the manufacturer's instruction. The concentration of extracted DNA was measured using a microvolume spectrophotometer (Genova Nano, Jenway). The extracted DNA sample (2 $\mu \mathrm{l})$ was transferred to the Genova Nano micro-volume spectrophotometer and concentration of DNA in microgram per milli-liter was measured. To assess the purity of DNA, the ratio of absorbances was taken at $260 \mathrm{~nm}$ and $280 \mathrm{~nm}$.

\section{Quantification of serum calcium and phosphorus}

Measurement of serum calcium levels was performed with atomic absorption spectrophotometer (HITACHI, 170-30) and phosphorus levels were determined by UV VIS spectrophotometer (Analytik Jena SPEKOL 2000). Briefly, collected samples were diluted with deionized water and the dilution factor was 10 . Calibration curve was prepared from the different concentrations $(0.5,1.0,5.0,10.0$ and $12.0 \mathrm{mg} / \mathrm{L}$ ) of standard calcium and phosphorus. Finally, the concentrations of calcium and phosphorus were measured by reading the absorbance at $422.7 \mathrm{~nm}$ for calcium and $710 \mathrm{~nm}$ for phosphorus, respectively. The test quality and precision were confirmed by running one standard solution for every 10 test samples. Five blank solutions were analysed to establish the limits of detection (LoDs) for serum calcium and phosphorus. Microsoft office Excel 2010 program was run to determine the $\sigma$ value. LoDs were observed as $1.5 \mu \mathrm{g} / \mathrm{L}$ for calcium and $0.01 \mu \mathrm{g} / \mathrm{L}$ for phosphorus. Serum calcium and phosphorus levels were calculated by SpectrAA software package using the calibration curve.

\section{Genotyping}

Two tagging SNPs of ORAI1 (rs12313273 and rs6486795) with a minor allele frequency (MCFs) of $>10 \%$ were selected from HapMap database. The PCR-RFLP method was applied to determine the ORAI1 gene polymorphisms. The fragments of ORAI1 were amplified by PCR using forward primers of 5'-AACGCTCCAACAGCCAAATA-3' and reverse primers of 5'-

GGAGAGGGGCAGGAAATAAG-3' and another forward primer of 5'-

ACGCCTGGACTGAGAAGTAC-3' and reverse primers of 5'-TAAAGAACGCCAGGCCAAAC-3', followed by gel electrophoresis for visualization. DNA ladders (50bp and 100bp) were also used for size estimation of all restriction enzyme digestion fragments, allowing for precise and reliable genotyping of samples.

\section{Statistical analysis}




\section{Cureus}

Independent sample $t$-test and cross table variables were used to compare all the parameter of non-dialysis CKD patients and controls. Mann-Whitney U test and Fisher's exact test were performed to evaluate differences between the groups. The linear association between variables was assessed by the Spearman's rank correlation coefficient test. For all the tests $\mathrm{p} \leqslant$ 0.05 was considered statistically significant. Statistical Package for Social Sciences (SPSS) version 23.0 (IBM Corp., Armonk, NY) was used to perform all those tests.

\section{Results}

The distribution of characteristics and laboratory findings of participants are presented in Table 1.

\begin{tabular}{|c|c|c|c|}
\hline Parameters & Patients ( $N=96)$ & Controls $(\mathrm{N}=100)$ & p-value \\
\hline Age in years, mean $\pm S D$ & $45.46 \pm 12.29$ & $42.76 \pm 12.60$ & 0.202 \\
\hline Gender, male/female & $50 / 46$ & $53 / 47$ & 0.631 \\
\hline BMI $\left(\mathrm{kg} / \mathrm{m}^{2}\right)$, mean $\pm \mathrm{SD}$ & $26.51 \pm 2.02$ & $26.26 \pm 2.62$ & 0.518 \\
\hline Smoker (\%) & $34 \%$ & $30 \%$ & 0.362 \\
\hline Serum calcium (mg/dL) & $2.53 \pm 0.50$ & $3.77 \pm 0.42$ & $<0.001$ \\
\hline Serum phosphorus (mg/dL) & $3.67 \pm 2.37$ & $13.66 \pm 6.34$ & $<0.001$ \\
\hline
\end{tabular}

\section{TABLE 1: Characteristics and clinical outcomes of the study population}

Significant $p$-values $\leq 0.05$ at $95 \%$ confidence interval; values in bold: $p<0.05$

BMI, body mass index; SD, standard deviation; N, number

The controls and the patients were recruited as similar age, gender and BMI with no significant variation $(p \geqslant 0.05)$, whereas in the laboratory analysis, there were significant differences $(p \leqslant$ 0.05 ) of serum calcium and phosphorus between patients and control group. Significantly reduced levels of calcium and phosphorus were observed in non-dialysis CKD patients compared to healthy individuals. A significant positive correlation $(r=0.582 ; p<0.001)$ was observed between serum calcium and phosphorus levels in non-dialysis CKD patients. Two tagging SNPs of ORAI1 (rs12313273 and rs6486795) with a minor allele frequency were selected from the HapMap database. In both cases, genetic analysis revealed a maximum number of TT genotype, normal homozygous with a few heterozygotes. However, no significance mutation was shown in respective SNPs (Table 2). 


\section{Cureus}

\begin{tabular}{|c|c|c|c|c|c|c|}
\hline & Genotype & Allele & Patients (\%) $(\mathrm{N}=96)$ & Controls $(\%)(N=100)$ & Genotype p-value & Allelic p-value \\
\hline & TT & $\mathrm{T}$ & $89(92.7)$ & $99(99.0)$ & & \\
\hline \multirow[t]{3}{*}{ rs 12313273} & CT & $\mathrm{C}$ & $5(5.2)$ & $1(1.0)$ & 0.462 & 0.532 \\
\hline & $\mathrm{CC}$ & & $2(2.1)$ & $0(0.0)$ & & \\
\hline & TT & $\mathrm{T}$ & $91(94.8)$ & $100(100.0)$ & & \\
\hline \multirow[t]{2}{*}{ rs6486795 } & CT & C & $4(4.2)$ & $0(0.0)$ & 0.173 & 0.361 \\
\hline & CC & & $1(1.0)$ & $0(0.0)$ & & \\
\hline
\end{tabular}

\section{TABLE 2: Genotyping and allele frequency of ORAl1 gene among study population}

Significant $p$-values $\leq 0.05$ at $95 \%$ confidence interval

$\mathrm{N}$, number

Associations of the ORAI1 gene with altered serum calcium and phosphorus levels in CKD patients are presented in Table 3.

\begin{tabular}{|c|c|c|c|c|c|c|}
\hline & Genotype & Patients (\%) $(\mathrm{N}=96)$ & Calcium (mg/dL) & $p$-value & Phosphorus (mg/dL) & $p$-value \\
\hline & TT & $89(92.7)$ & $2.59 \pm 0.52$ & & $3.67 \pm 0.83$ & \\
\hline \multirow[t]{3}{*}{ rs12313273 } & CT & $5(5.2)$ & $2.40 \pm 0.17$ & 0.354 & $2.38 \pm 0.36$ & 0.211 \\
\hline & $\mathrm{CC}$ & $2(2.1)$ & $2.48 \pm 0.81$ & & $3.41 \pm 0.91$ & \\
\hline & TT & $91(94.8)$ & $2.59 \pm 0.62$ & & $3.68 \pm 0.42$ & \\
\hline \multirow[t]{2}{*}{ rs6486795 } & CT & $4(4.2)$ & $2.37 \pm 0.16$ & 0.243 & $2.48 \pm 0.46$ & 0.152 \\
\hline & $\mathrm{CC}$ & $1(1.0)$ & $2.62 \pm 0.00$ & & $3.23 \pm 0.00$ & \\
\hline
\end{tabular}

TABLE 3: Difference in the calcium and phosphorus levels in non-dialysis CKD patients stratified by different ORAl1 genotype

Significant $p$-values $\leq 0.05$ at $95 \%$ confidence interval

CKD, chronic kidney disease; N, Number

\section{Discussion}

Latest studies on the genetic susceptibility and the development of CKD have yielded promising results. The results of a genome-wide association study showed that several loci were associated with CKD and estimated glomerular filtration rate (eGFR) [17]. A major correlation 
was found between TRPC1, ORAI1, STIM1 and parathyroid cells $[13,18]$. Some recent studies in Asia revealed the significance of the ORAI1 gene in calcium regulation among CKD patients. Chou et al. demonstrated an association of ORAI1 with the risk and recurrence of calcium nephrolithiasis in Taiwanese people [19]. Another study in the same region found that ORAI1 polymorphism was linked with increased serum calcium [13]. Mineral abnormalities such as elevated calcium, phosphorus, and PTH are found in non-dialysis CKD patients that later on contributing increased death in CKD patients [20-22]. However, there was no previous study investigating the influence of calcium and phosphorus regulating channels in case of CKD patients in Bangladesh. As we also belong to an Asian country, we conducted this study in order to observe if there was any similarity pattern between our outcomes and previous findings or not.

In our study, after genotyping of SNPs of ORAI1 (rs12313273 and rs6486795), no mutation was found rather than some minor heterozygotes. On the other hand, the results of serum calcium and phosphorus were found in much-declined levels compared to healthy subjects. It is already established that low levels of calcium, phosphorus in early staged CKD patients eventually turned into hypercalcemia and hyperphosphatemia which is directly linked to vascular calcification- the most frequent cause of death in CKD $[3,6,10]$.

Calcium influxes in T cells through the CRAC channels whereas ORAI1 is essential for the function of CRAC channels [23-27]. From the recent study of Hwang et al, five ORAI1 tagging SNPs such as rs12313273, rs6486795, rs7135617, rs12320939, and rs712853 were investigated among Taiwanese CKD patients [13]. None of the tSNPs of ORAI1 were associated with the risk of CKD except polymorphism of rs12313273 ORAI1 gene which was significantly associated with elevated serum calcium levels. As our study revealed a significant decrease of serum calcium and phosphorus level in non-dialysis CKD patients, we expected some linear correlation with ORAI1 thus found no significant mutation of rs12313273 and rs6486795.

There were some limitations in our study. First, we did not consider other factors that can be correlated with serum calcium levels and other comorbidities were not identified during sample collection. Second, the sample size was little and we recruited only the urban population which cannot be the representative of the whole population. Our results revealed that the association of ORAI1 genotype with calcium and phosphorus levels as we found neither elevation of calcium level nor the alteration of these SNPs. That is why extensive studies with a large population are needed to fully understand the linkage between ORAI1 and altered calcium and phosphorus levels.

\section{Conclusions}

To the best of our knowledge, this is the first study in Bangladeshi CKD patients examining ORAI1 gene polymorphism with serum calcium and phosphorus. Though our study yields no correlation, further replication studies with large cohort should be carried out to clarify the effect of ORAI1 genetic polymorphism in CKD.

\section{Additional Information \\ Disclosures}

Human subjects: Consent was obtained by all participants in this study. Ethical review committee at the department of nephrology, NIKDU, and HFRCMCH. issued approval N/A. The study protocol was approved by the ethical review committee at the department of nephrology, NIKDU, and HFRCMCH. All investigations were conducted according to the principles expressed in the Declaration of Helsinki. The study participants were well informed about the objective of the study and written consent was taken from each of them or their caregivers. 
Animal subjects: All authors have confirmed that this study did not involve animal subjects or tissue. Conflicts of interest: In compliance with the ICMJE uniform disclosure form, all authors declare the following: Payment/services info: All authors have declared that no financial support was received from any organization for the submitted work. Financial relationships: All authors have declared that they have no financial relationships at present or within the previous three years with any organizations that might have an interest in the submitted work. Other relationships: All authors have declared that there are no other relationships or activities that could appear to have influenced the submitted work.

\section{Acknowledgements}

The authors are thankful to all the staff and physicians at the department of nephrology, NIKDU, and HFRCMCH, for their technical and administrative support. The authors are also thankful for the laboratory support provided by the department of soil science, Bangabandhu Sheikh Mujibur Rahman Agricultural University, Salna, Gazipur-1706, Bangladesh.

\section{References}

1. Levey AS, Coresh J: Chronic kidney disease. Lancet. 2012, 379:165-80. 10.1016/S01406736(11)60178-5

2. Gifford F, Kimmitt R, Herath C, et al.: Arterial stiffness \& Sri Lankan chronic kidney disease of unknown origin. Sci Rep. 2016, 6:32599. 10.1038/srep32599

3. Hruska KA, Mathew S, Lund R, Qiu P, Pratt R: Hyperphosphatemia of chronic kidney disease . Kidney Int. 2008, 74:148-57. 10.1038/ki.2008.130

4. Hill NR, Fatoba ST, Oke JL, Hirst JA, O'Callaghan CA, Lasserson DS, Hobbs FD: Global prevalence of chronic kidney disease: a systematic review and meta-analysis. PLoS One. 2016, 11:0158765. 10.1371/journal.pone.0158765

5. Anand S, Khanam MA, Saquib J, et al.: High prevalence of chronic kidney disease in a community survey of urban Bangladeshis: a cross-sectional study. Global Health. 2014, 10:9. 10.1186/1744-8603-10-9

6. Cozzolino M, Dusso AS, Slatopolsky E: Role of calcium-phosphate product and boneassociated proteins on vascular calcification in renal failure. J Am Soc Nephrol. 2001, 12:25112516.

7. Mitsnefes MM, Kimball TR, Kartal J, et al.: Cardiac and vascular adaptation in pediatric patients with chronic kidney disease: role of calcium-phosphorus metabolism. J Am Soc Nephrol. 2005, 16:2796-803. 10.1681/ASN.2005030291

8. Levin A, Bakris GL, Molitch M, Smulders M, Tian J, Williams LA and Andress DL: Prevalence of abnormal serum vitamin D, PTH, calcium, and phosphorus in patients with chronic kidney disease: results of the study to evaluate early kidney disease. Kidney Int. 2007, 71:31-8. 10.1038/sj.ki.5002009

9. Sarnak MJ, Coronado BE, Greene T, Wang SR, Kusek JW, Beck GJ, Levey AS: Cardiovascular disease risk factors in chronic renal insufficiency. Clinical Nephrol. 2002, 57:327-33.

10. Kestenbaum B, Sampson JN, Rudser KD, et al.: Serum phosphate levels and mortality risk among people with chronic kidney disease. J Am Soc Nephrol. 2005, 16:520-8. 10.1681/ASN.2004070602

11. Shanahan CM, Crouthamel MH, Kapustin A, Giachelli CM: Arterial calcification in chronic kidney disease: key roles for calcium and phosphate. Circ Res. 2011, 109:697-711. 10.1161/CIRCRESAHA.110.234914

12. McCarron DA: Protecting calcium and phosphate balance in chronic renal disease . J Am Soc Nephrol. 2005, 16:93-4. 10.1681/ASN.2005060661

13. Hwang DY, Chien SC, Hsu YW, et al.: Genetic polymorphisms of ORAI1 and chronic kidney disease in Taiwanese population. Biomed Res Int. 2014, 2014:290863. 10.1155/2014/290863

14. Langman CB, Cannata-Andía JB: Calcium in chronic kidney disease: myths and realities . Clin J Am Soc Nephrol. 2010, 5:1-2. 10.2215/CJN.06140809

15. Lacruz RS, Feske S: Diseases caused by mutations in ORAI1 and STIM1 . Ann N Y Acad Sci. 2015, 1356:45-79. 10.1111/nyas.12938

16. Earle KA, Zitouni K, Pepe J, Karaflou M, Godbold J Jr: Modulation of endogenous antioxidant 
defense and the progression of kidney disease in multi-heritage groups of patients with type 2 diabetes: prospective evaluation of early nephropathy and its treatment (prevent). J Transl Med. 2016, 14:234. 10.1186/s12967-016-0975-9

17. Köttgen A, Glazer NL, Dehghan A, et al.: Multiple loci associated with indices of renal function and chronic kidney disease. Nat Genet. 2009, 41:712-7. 10.1038/ng.377

18. Lu M, Bränström R, Berglund E, et al.: Expression and association of TRPC subtypes with Orai1 and STIM1 in human parathyroid. J Mol Endocrinol. 2010, 44:285-94. 10.1677/JME-090138

19. Chou YH, Juo SH, Chiu YC, et al.: A polymorphism of the ORAI1 gene is associated with the risk and recurrence of calcium nephrolithiasis. J Urol. 2011,185, 1742:6. 10.1016/j.juro.2010.12.094

20. Kalantar-Zadeh K, Shah A, Duong U, Hechter RC, Dukkipati R, Kovesdy CP: Kidney bone disease and mortality in CKD: revisiting the role of vitamin D, calcimimetics, alkaline phosphatase, and minerals. Kidney Int Suppl. 2010, 10:21. 10.1038/ki.2010.189

21. National Kidney Foundation: K/DOQI clinical practice guidelines for chronic kidney disease: evaluation, classification, and stratification. Am J Kidney Dis. 2002, 39:1-266.

22. Schwarz S, Trivedi BK, Kalantar-Zadeh K, Kovesdy CP: Association of disorders in mineral metabolism with progression of chronic kidney disease. Clin J Am SocNephrol. 2006, 1:82531. 10.2215/CJN.02101205

23. Feske S, Okamura H, Hogan PG, Rao A: Ca2+/calcineurinsignalling in cells of the immune system. Biochem Biophys Res Commun. 2003, 311:1117-32.

24. Feske S, Prakriya M, Rao A, Lewis RS: A severe defect in CRAC Ca2+ channel activation and altered K+ channel gating in T cells from immunodeficient patients. J Exp Med. 2005, 202:65162.

25. Feske S, Gwack Y, Prakriya M, et al.: A mutation in Orai1 causes immune deficiency by abrogating CRAC channel function. Nature. 2006, 441:179-85. 10.1038/nature04702

26. Gallo EM, Canté-Barrett K, Crabtree GR: Lymphocyte calcium signaling from membrane to nucleus. Nat Immunol. 2006, 7:25-32. 10.1038/ni1295

27. Lewis RS: Calcium signaling mechanisms in T lymphocytes . Annu Rev Immunol. 2001, 19:497-521. 10.1146/annurev.immunol.19.1.497 